\title{
The role of village leaders in the implementation of multidrug therapy for leprosy, Sudan-a pilot study in the Angasana Hills
}

\author{
K. M. AHMED \& M. S. EL TAHIR \\ POB 10616, Leprosy Programme, Khartoum, Sudan
}

Accepted for publication 24 October 1995

Summary The purpose of this study is to implement multidrug therapy (MDT) and to evaluate the possible role of village leaders in supervising MDT treatment in remote and inaccessible areas in Sudan where health facilities are poor.

Three villages from the Angasana Hills in the south-east of Sudan, where leprosy is endemic, have been chosen for this study.

A health education course for village leaders in the area was conducted. Three medical assistants from a nearby village were identified to examine all leprosy suspects and to put the diagnosed cases on treatment. The village leaders were to supervise the treatment of the patients during the rainy season.

Out of 43 cases detected all paucibacillary (PB) cases detected (11 cases) completed their treatment and 28 out of 32 multibacillary (MB) cases were regularly on treatment.

It has been obvious that the village leaders were useful in supervising MDT in the Angasana area, a process which can be extended to other inaccessible areas in the Sudan.

\section{Introduction}

Sudan is one of the biggest countries in Africa with a surface area of one million square miles, and a population of 24 millions. It is bounded by nine countries. It has different types of climates, the Equatorial climate in the south, the Savanna in the centre and the desert in the north. Sudan is divided into 26 states, the majority of the population is rural. Due to the vastness of the country, there is a problem of communication between different states, especially in the western and southern states, and that is made more worse during the rainy season. The health infrastructure is inadequate in many places in the western and eastern states. But health infrastructure in the south is very poor due to the state of insecurity resulting from the war in the south of Sudan since 1983.

Leprosy is a well-known disease in Sudan. It is mainly prevalent in the eastern, central and southern states. The estimated number of leprosy patients in Sudan is 24,850 (Figure 1$)^{1}$. The total number of new patients showed a progressive rise from 600 patients in 1990 to 3070 patients at the end of 1994 . Though leprosy control activities started in the early seventies, intensification of leprosy activities was achieved in 1992 


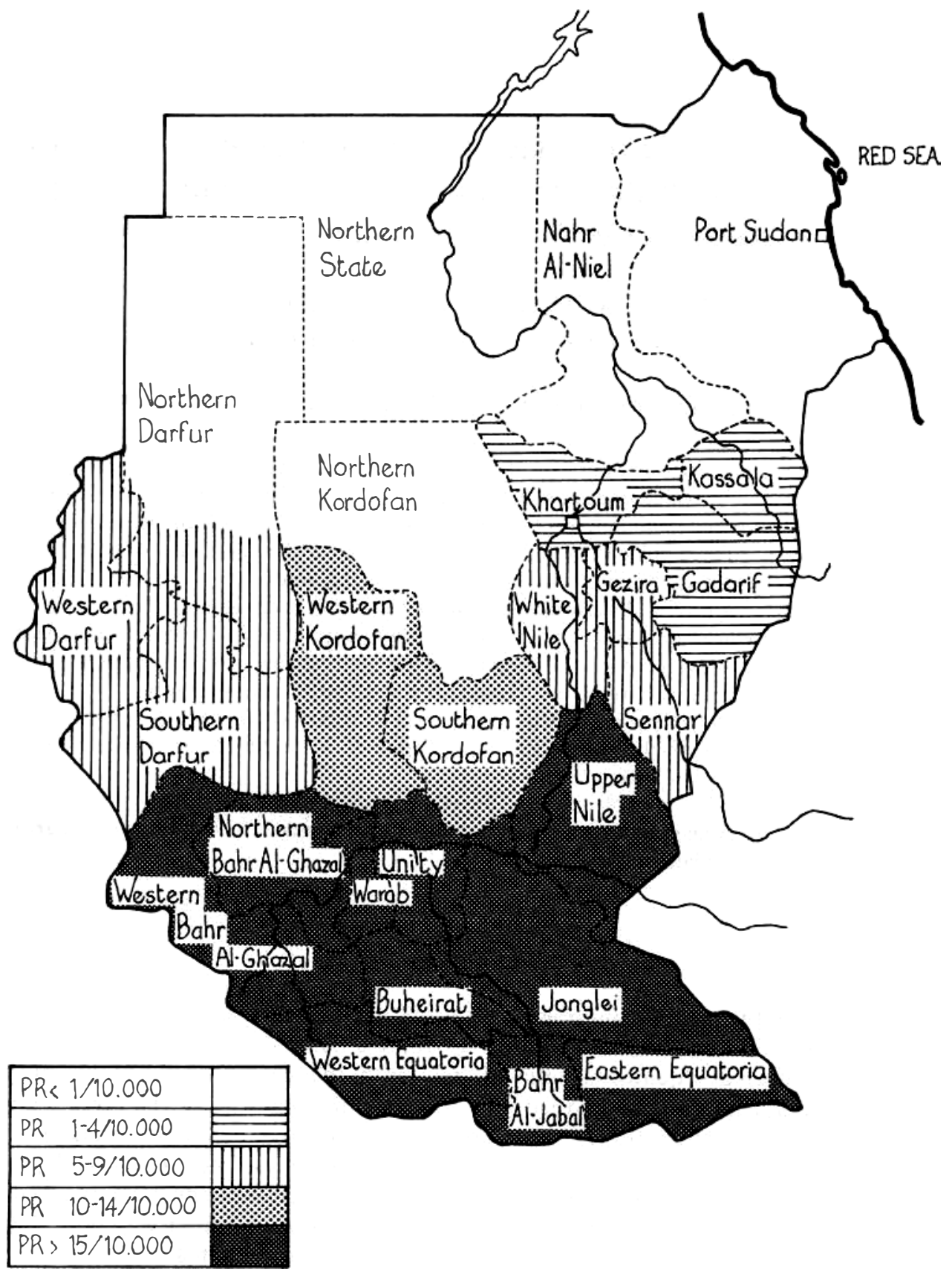

Figure 1. States of the Sudan, 14 February 1994. Estimated prevalence. 


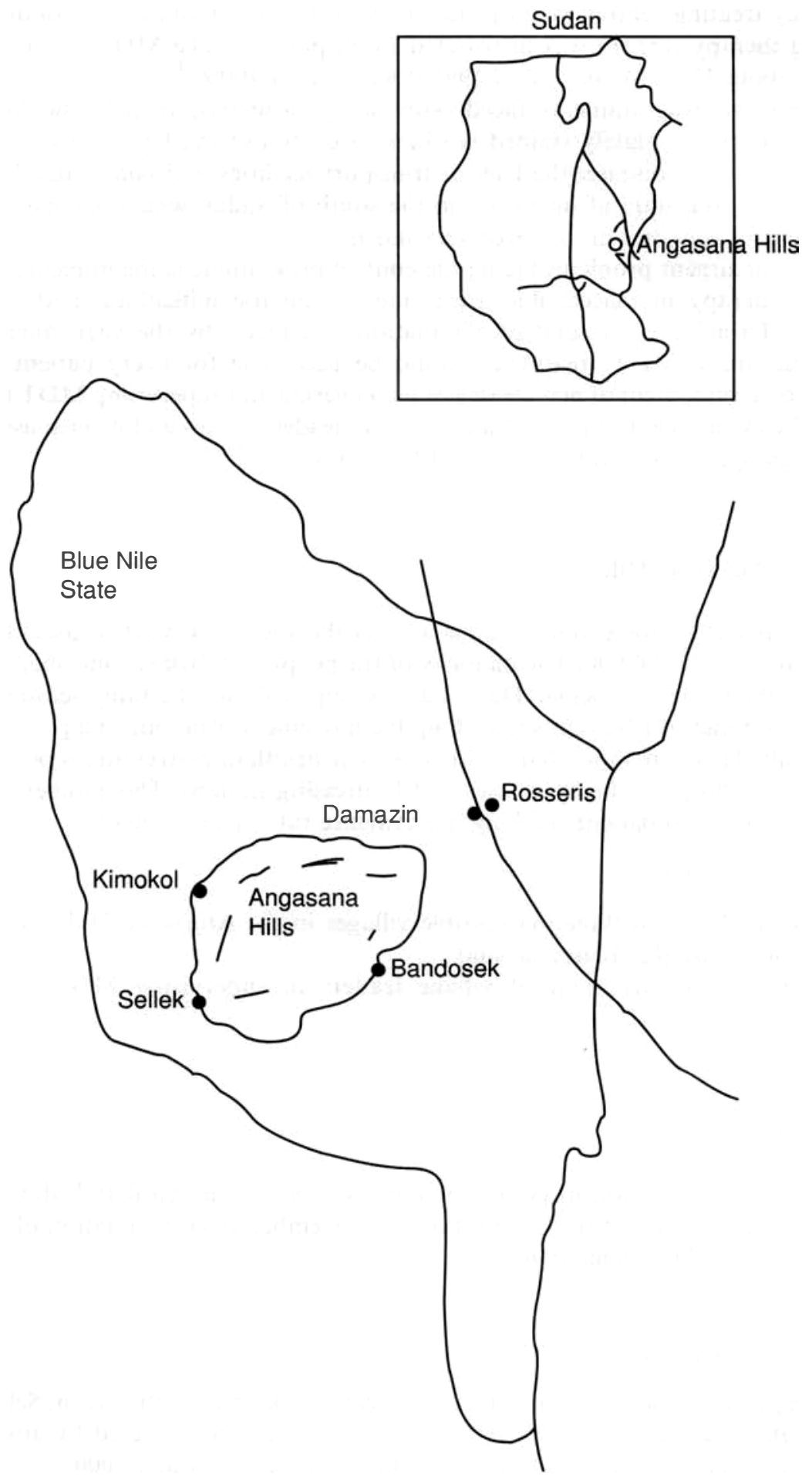

Figure 2. The Angasana Hills and surrounding districts. 
when many treating centres were opened; many training activities were conducted and multidrug therapy (MDT) was distributed to all patients. The MDT coverage before 1992 was about $13 \%$, by the end of 1994 it was almost $100 \%{ }^{1}$

The leprosy programme is faced with many problems, namely the inadequate infrastructure, inadequately trained workers to carry out the leprosy work; the high social stigma of the disease; the lack of transport facilities and bad roads; long rainy seasons; beside the state of insecurity in the south of Sudan which has hampered the leprosy control activities in that area very much.

One of the urgent problems facing the control programme is the implementation of multidrug therapy in inaccessible areas due to climatic difficulties, bad roads and insecurity. To achieve the goal of elimination of leprosy by the year 2000 in those inaccessible areas, MDT treatment should be accessible for every patient and this necessitates development of new strategies in delivering and supervising MDT treatment through the involvement of public leaders, village leaders, youth and women associations and through Special Action Project (SAPEL) intervention. ${ }^{8}$

\section{Study area: Angasana Hills}

The Angasana Hills are a mountainous area in the south-east part of the Sudan. The population is about 100,000 . The majority of the people are farmers and shepherds and the main tribe is the Angasana. The roads are unpaved and the rainy season starts in June and continues till November, making the movement from one village to the other very difficult. There are more than 30 villages. The health infrastructure is poor: there is only one small hospital, 4 dispensaries and 12 dressing stations. The number of leprosy patients is about 280 patients making a prevalence rate of $28 / 10,000 .^{2}$

Objectives of the study:

To implement MDT in three inaccessible villages in the Angasana Hills using village leaders to supervise the treatment; and

To evaluate the involvement of village leaders in supervising MDT for leprosy patients.

\section{Methodology}

The study started two months before the rainy season, i.e., in April and May 1994 and included the whole rainy season from June to November 1994. Evaluation of the study was conducted in December 1994.

\section{SELECTION OF THE AREA}

Three villages from the Angasana Hills were selected. Kimrol in the north, Sellek in the west and Bandosek in the south. All three villages were not covered by any form of health service. The total population in the three villages is about 12,000 . 
SEMINAR FOR VILLAGE LEADERS

A seminar for 30 leaders from different villages in Angasana including the three chosen villages was conducted in March 1994. It was concerned with increasing the awareness of the leaders about leprosy, its aetiology and treatment, and the importance of early detection and early treatment of leprosy cases.

EXPeCted Duties of Village Leaders include:

Presenting suspected cases with visible deformities or with suspected skin lesions to be examined by the medical assistant; and

supervision of treatment of leprosy patients during the rainy season from June to November 1994.

\section{SELECTION OF THE MEDICAL ASSISTANTS}

Three medical assistants from the nearby villages covered by the health service were chosen. Each medical assistant visited one village once a month during April and May.

DUTIES OF THE MEDICAL ASSISTANT INCLUDED THE FOLLOWING

To examine suspected leprosy cases;

to diagnose, treat and register leprosy cases;

to educate the patients about the disease and the importance of regularity in treatment; and

to present a report about his activities at the end of the year.

SELECTION OF PATIENTS

All suspected leprosy patients in the village were brought by the village leaders to the medical assistants during their monthly visits in April and May 1994.

All diagnosed leprosy patients were classified according to the WHO classification ${ }^{3}$ and put on the recommended WHO regimen of multidrug therapy. ${ }^{4}$ Patients were given supervised treatments by the medical assistants in April and May 1994. Six months treatment was given to each patient to cover the period of the rainy season.

\section{DIAGNOSIS OF PATIENTS}

Diagnosis was mainly on clinical grounds depending on the presence of the cardinal signs for leprosy. ${ }^{5}$

\section{CLASSIFICATION}

Classification of leprosy was according to the national guidelines in the national manual. 


\section{Paucibacillary}

Patient with well-defined anaesthetic skin lesion with or without peripheral nerve enlargement, the number of both skin lesions and enlarged peripheral nerves should not exceed five.

\section{Multibacillary}

When the number of both the skin lesions and enlarged peripheral nerves exceeded five.

Disability Grading was carried out according to WHO grading for disability. ${ }^{6}$

\section{SUPERVISION}

The Co-investigator visited the villages in December 1994 and performed the following activities:

interviewed and examined all available patients;

interviewed the village leaders; and

checked the patient registers.

\section{INDICATORS}

The following indicators were used;

total number of patients detected;

detection rate;

proportion of newly detected PB and MB cases;

proportion of Grade II disability in new detected cases;

number of PB patients completed MDT

number of $\mathrm{PB}$ patients expected to complete MDT;

number of $\mathrm{MB}$ patients completed 8 doses

total number of MB cases put on MDT

\section{Results}

Out of the 127 suspected cases 43 leprosy cases have been identified making a case detection rate of $36 / 10,000$. The male to female ratio was $1 \cdot 3 / 1 \cdot 0$. Total of MB cases detected was 32 patients (74\%) and total of PB cases detected was $11(26 \%)$.

The mean age was 32 years. No patients below 15 years of age were detected. Grade II disability was noticed in $3 \mathrm{MB}$ patients $(7 \%)$ and Grade I disability was noticed in another $3 \mathrm{MB}$ patients. The remaining patients showed no disability.

All patients were put on MDT treatment according to the guidelines. All PB cases completed their six doses and discharged from treatment.

All MB patients except four completed their treatment from April to November 1994. (See Tables 1 and 2.) 
Table 1. No. and classification of patients detected in each village

\begin{tabular}{|c|c|c|c|c|c|c|}
\hline \multirow[b]{2}{*}{ Village } & \multicolumn{2}{|c|}{ MB } & \multicolumn{2}{|c|}{ PB } & \multicolumn{2}{|c|}{ Total } \\
\hline & Male & Female & Male & Female & MB & $\mathrm{PB}$ \\
\hline Bandosek & 5 & 6 & 5 & 1 & 11 & 6 \\
\hline Sillek & 6 & 4 & 2 & 1 & 10 & 3 \\
\hline Kimrol & 5 & 6 & 1 & 1 & 11 & 2 \\
\hline Total & 16 & 16 & 8 & 3 & 32 & 11 \\
\hline
\end{tabular}

Table 2. Classification, disability grading, No. of MDT doses received and No. of defaulters

\begin{tabular}{|c|c|c|c|c|c|c|c|c|}
\hline & \multicolumn{2}{|c|}{ PB } & \multicolumn{2}{|c|}{ MB } & \multirow{3}{*}{$\begin{array}{c}\text { PB } \\
\text { Completed } \\
6 \\
\text { doses }\end{array}$} & \multirow{3}{*}{$\begin{array}{c}\mathrm{MB} \\
\text { Completed } \\
8 \\
\text { doses }\end{array}$} & & \\
\hline & \multirow{2}{*}{$\begin{array}{c}\text { Without } \\
\text { disabilities } \\
\text { Grade II }\end{array}$} & \multirow{2}{*}{$\begin{array}{c}\text { With } \\
\text { disabilities } \\
\text { Grade II }\end{array}$} & \multirow{2}{*}{$\begin{array}{l}\text { Without } \\
\text { disabilities } \\
\text { Grade II }\end{array}$} & \multirow{2}{*}{$\begin{array}{c}\text { With } \\
\text { disabilities } \\
\text { Grade II }\end{array}$} & & & \multicolumn{2}{|c|}{ Default. } \\
\hline & & & & & & & PB & $\mathrm{MB}$ \\
\hline Bandosek & 6 & - & 11 & - & 6 & 10 & - & 1 \\
\hline Sillek & 3 & - & 9 & 1 & 3 & 8 & - & 2 \\
\hline Kimrol & 2 & - & 9 & 2 & 2 & 10 & - & 1 \\
\hline Total & 11 & - & 29 & 3 & 11 & 28 & - & 4 \\
\hline
\end{tabular}

\section{Discussion}

It is clear from the results that the village leaders were able to perform their duties well. This was evident by the increased leprosy awareness among the community and the detection of 43 new cases, which was a relatively big number compared to the number of new cases detected in other villages in the same area. Although the number of women reporting for treatment was slightly less than that of the males, it was considered a relatively high figure compared to the number of women detected in other areas in the country. It is a well-known fact that women in the rural areas in Sudan refrain from being examined clinically by men. Detection of such a figure among women reflects their great concern and awareness about the disease.

Also, as expected in a new area, the majority of the patients were of the multibacillary type. $^{7}$ Achievements of these activities in the three villages reflects the great input of the community leaders in promoting the awareness of the population about leprosy and bringing patients for treatment.

Another point of consideration is that, Grade II disability is a figure $7 \%$ less than the lowest rate of disability in new patients detected in other areas in the Sudan which ranged from 15 to $30 \%$. This is explained by the early detection and early reporting of cases for treatment in the study area.

Regarding the compliance of patients, the results were excellent and very encouraging. All PB cases completed the treatment and 28 out of $32 \mathrm{MB}$ cases $(88 \%)$ were quite regular in taking treatment, and the remaining 4 cases took only 2 doses and they disappeared from 
the area. Further follow-up of the MB patients on treatment is to be carried out to monitor their regularity and compliance to treatment.

The recent implementation of the first phase of the special action project (SAPEL) for South Kordofan State $^{9}$ demonstrated clearly the important role of the public and village leaders in implementation of MDT therapy. They have been quite helpful in promoting leprosy control activities by bringing up cases for treatment, supervising patients' treatment, tracing the absentees. ${ }^{9}$ Further implementation of such activities using the village leaders in other areas will promote leprosy activities and give a better evaluation of the process of involvement of such important sectors of the community in leprosy control activities. The elimination of leprosy cannot be achieved in such special areas without the involvement of those sectors.

In conclusion it has been quite obvious that involvement of community leaders in the field of leprosy is very important and perhaps should be mandatory in certain areas where the health facilities are poor or in areas which are geographically inaccessible.

\section{References}

1 Leprosy Annual Report 1994, Leprosy Control Programme, Ministry of Health, Sudan.

2 Leprosy Annual Report 1994, Leprosy Control Programme, Central State, Sudan.

3 Classification of Leprosy, WHO expert Committee on Leprosy 1988.

4 Multidrug Therapy for Leprosy Control, Chemotherapy of Leprosy, WHO Expert Committee on Leprosy 1988, page 30-32.

5 Pfaltzgraff RE, Bryceson A. Cardinal signs of Leprosy, Clinical Leprosy, Leprosy by R. Hastings, 1985, pp. 134-74.

${ }^{6}$ Grading of Disabilities, WHO Expert Committee 1988, page 35.

7 A guide to leprosy control, second edition 1988, page 81 .

8 Special Action Project, Report of the International Conference o n Elimination of Leprosy, WHO, 1994, page 21.

9 Technical report of the implementation of the first phase of the special action project for South Kordofan State, leprosy control programme 1995, Sudan. 